Article

\title{
The Effect of Cultural Intelligence, Conflict, and Transformational Leadership on Decision-Making Processes in Virtual Teams
}

\author{
Vida Davidaviciene *(1) and Khaled Al Majzoub
}

check for

updates

Citation: Davidaviciene, Vida, and Khaled Al Majzoub. 2022. The Effect of Cultural Intelligence, Conflict, and Transformational Leadership on Decision-Making Processes in Virtual Teams. Social Sciences 11: 64. https://doi.org/10.3390/socsci 11020064

Academic Editors: Beata Ślusarczyk, Aneta Pachura and Hana Štverková

Received: 2 December 2021

Accepted: 28 January 2022

Published: 8 February 2022

Publisher's Note: MDPI stays neutral with regard to jurisdictional claims in published maps and institutional affiliations.

Copyright: (C) 2022 by the authors. Licensee MDPI, Basel, Switzerland. This article is an open access article distributed under the terms and conditions of the Creative Commons Attribution (CC BY) license (https:// creativecommons.org/licenses/by/ $4.0 /)$.
Department of Business Technologies and Entrepreneurship, Business Management Faculty, Vilnius Tech University, Saulètekio al. 11, 10223 Vilnius, Lithuania; khaledmajzoub@hotmail.com

* Correspondence: vida.davidaviciene@vilniustech.lt

\begin{abstract}
The rapid development of information and communication technology (ICT) has resulted in several improvements in diverse aspects of the organizational structures, including the introduction of virtual teams (VTs). Organizations rely on VTs since they bring a lot of benefits, such as the enhancement of organizational performance. However, effective VTs cannot exist without the proper implementation of decision-making processes. There is a lack of scientific research that attempts to understand the factors affecting decision-making processes in VTs. Studies in this area have only been conducted in the United States and Europe. However, such research has not been conducted in the Middle East, where specific scientific solutions are still required to improve the performance of VTs. Therefore, this study is conducted in the Middle East to gain scientific knowledge on this region's specificity. Thus, the objective of this study is to identify the factors that affect VT decision-making processes. An online survey was used to collect data (Google forms) from companies in the IT industry in UAE, which are engaged in VTs. A literature review, survey methods, and structural equation modeling were used. The results showed that culture intelligence (CQ), transformational leadership (TL), and task conflict have a positive effect on VT decision-making processes, and relationship conflict has a negative impact on VT decision-making processes, which provides the management teams with a guideline on what to concentrate on in the measuring and enhancement of the effectiveness of VT decision making.
\end{abstract}

Keywords: cultural intelligence; decision-making processes; relationship conflict; task conflict; transformation leadership; virtual teams

\section{Introduction}

The most important changes that face organizations are caused by information and communication technology (ICT) (Al Majzoub and Davidavičienè 2018). ICT has caused the formation of a new type of team work called virtual teams. The use of virtual teams is important for organizations because they allow team members to communicate, despite distance and time constraints. They allow organizations to hire the most talented people regardless of the location, which increases the efficiency of the team (Schmidtke and Cummings 2017). VTs are defined as "groups of people who are geographically and/or organizationally dispersed and who rely on collaboration technologies to carry out tasks" (Lowry et al. 2015). VTs bring advantages to organizations, such as the presence of diverse staff, innovation allocation of resources, flexible organizational structure, enhanced decision making and an increase in organizational performance (Bhat et al. 2017). Even though VTs provide benefits to the organization, they impose challenges to perform effectively. One of the essential factors that affects VT performance is decision-making processes (Wei et al. 2017). To date, there exists a case of scarcity in academic research in the field of decisionmaking processes in virtual teams (Davidaviciene et al. 2020; Drouin and Bourgault 2013; Tan 2019; Zakaria 2017). Most of the research is conducted on university students instead 
of actual organizational virtual teams (O’Neill et al. 2016; Organ and Flaherty 2018; Paul and Dennis 2018). From the literature review, it could be concluded that there is a lack of research that examines the effect of these three factors - conflict, culture and leadership-on the decision-making process in UAE.

Therefore, the objective of this article is to examine the effect of the three factors culture intelligence (CQ), conflict (task and relationship), and transformational leadership on VT decision-making processes. The research question was formulated as follows: are cultural intelligence, conflict and transformational leadership positively correlated with decisionmaking processes? The study is conducted on the IT industry in UAE. The methodology used includes a literature review, survey methods, and structural equation modeling. In the next section, we review the literature on decision making and the factors that affect it and present our model, after which follows the Methodology Section and conclusions.

\section{Previous Studies and Hypothesis Development}

\subsection{Review of the Literature}

The authors identified several factors that affect VT decision-making processes. The following is a more detailed discussion of the key elements, i.e., cultural intelligence, transformational leadership, relationship, and task conflict. These factors were chosen for their prevalence in academic research on VTs as having the biggest impact on VT decision-making processes and are summarized in Table 1.

Table 1. Factors affecting the decision-making process of virtual teams.

\begin{tabular}{cc}
\hline Factor & Authors \\
\hline Decision-making processes & (Cordes 2016; Johnson et al. 2018; Oesch and Dunbar 2018; \\
Wei et al. 2017)
\end{tabular}

Decision-Making Process. Decision-making processes are the act of processing information to reach a judgment regarding a problem. Arriving to a decision requires people who will make the decision to weigh the potential gains and compare them to potential losses so as to choose the best available option (Glazer and Karpati 2018). Decision-making processes in virtual teams is an important component for their performance. The ability to effectively make decisions is crucial to the performance of the team, and a well-performed team will be able to make effective decisions. Decision-making processes in a virtual team are complex, and, to understand group decision dynamics, it is very important to look at the interaction pattern in group decision making since interaction is the essence of group decision making. Decisions made by virtual teams are not discrete, but they are generated by involving a series of activities and choices (Wei et al. 2017). In this article, decisionmaking processes were composed of three processes: (1) intelligence (understanding the problem); (2) design (generating alternatives); and (3) choice (choosing a decision from the alternatives). Decision-making processes in VTs are complex because they need to negotiate the multiple team members' opinions and ideas (Bartelt et al. 2013). Although virtual teams exchange more information than traditional teams (face-to-face teams), poor decisions are often the result. This is because team members do not consider the information they receive from other members. Members will experience a phenomenon called confirmation bias, which is the process whereby team members try to seek information that confirms their initial impression and ignore contradictory information, which results in poor decision making, and will affect team performance (Davidavičiene et al. 2020). Decisions that are made after information collection and analysis are found to be more effective, which is the key point differentiating successful performing teams and unsuccessful performing 
teams. Scholars (Cordes 2016; Johnson et al. 2018; Oesch and Dunbar 2018; Wei et al. 2017) found that successful teams tend to analyze the problem in depth before taking a decision about the solution, which is not the case in unsuccessful teams (Wei et al. 2017). In the next paragraphs, we review the factors that affect decision-making processes.

Conflict. The use of ICT between team members lacks verbal and non-verbal cues, which makes it difficult for team members to realize the existence of conflict. Conflict is defined as "the perception by the parties involved that they hold discrepant views or have interpersonal incompatibilities". Conflict between team members can occur for different reasons, such as cultural differences, group value consensus, demographic diversity, and functional diversity. Conflict can be categorized into two types: (1) task and (2) relationship conflicts. Relationship conflict between teams rises because of the difference in norms, values, behaviors, and attitudes. Task conflicts are about policies and procedures at the time of distributing resources or differences in interpreting facts to produce a judgment. Conflict can be either manifested or perceived. In perceived conflict, members are aware of the conflict, while in manifested conflict, members are not aware and its reflected in their overt behavior (Paul and Dennis 2018). Another type of conflict is identity-based conflict, which emerges from a dispute over the intrinsic value of a social group. This conflict is not work-related, and it originates when people from different identity groups try to work together. Social identity conflict is different from inter-personal conflict, which occurs when the other members in the group take sides based on gender, race, sex orientation, nationality, or religion. Social identity conflict is very hard to solve since it is charged with emotions. The conflict occurs either on competition over resources or feeling of threat by another identity group (Chrobot-mason et al. 2011).

In this article, we focused on task and relationship (interpersonal) conflict. Task and relationship conflicts are interrelated, and each one affects the other. Task conflict differs from interpersonal conflict since it does not include intense negative interpersonal emotions that exist in relationship conflicts (Wang et al. 2019). Diversity of ICT, culture, team size, and task function all are determinants of task and relationship conflict between team members (Chang et al. 2014; Wu 2020). Conflict will badly affect decision-making in the virtual team since it will make members uncomfortable and will avoid the sharing of unique information that enhances decision-making process (Derven 2016). Research has shown (Olson et al. 2007; Wang et al. 2019; Witman 2018; Zhang and Zhang 2019) that task conflict can enhance performance in non-routine and cognitive tasks, while personal conflict is detrimental for team decision making. Hence, conflict can act as functional and dysfunctional for team performance. Interpersonal conflict can be reflected into three key dimensional indicators: disagreement (divergence of values, needs, etc.), interference (for example, when one of team member opposes the attainment of other goals) and negative emotions (feelings such as anger, which is a result from disagreement or interference) (Wang et al. 2019). During decision making, functional diversity between VT members will cause task conflict because task conflict requires the exchange of ideas between members with different functional backgrounds, which synthesize different viewpoints into decision making. It will require some time between team members to form the "who knows what" perception. Task conflict enhances decision making due to the presentation of the different perspectives of team members (Wu 2020). Task conflict positively affects decision making, because it is considered to increase information and knowledge sharing (Kiernan et al. 2019; Susskind and Odom-reed 2019).

Based on the above literature, we propose the following hypothesis:

Hypothesis 1a (H1a). Relationship conflict affects decision-making processes negatively in VT.

Hypothesis $\mathbf{1 b} \mathbf{( H 1 b ) . ~ T a s k ~ c o n f l i c t ~ a f f e c t s ~ d e c i s i o n - m a k i n g ~ p r o c e s s e s ~ p o s i t i v e l y ~ i n ~ V T . ~}$

Transformational Leadership. Changing the organizational structure from hierarchical to a more flexible structure has forced leaders to find a new way to manage work. The 
success of an organization depends largely on leadership since leaders make a critical difference in team performance (Carita 2014). According to Maduka et al. (2018), leadership is defined as "the influencing of behaviors and attitude of individuals, including the interaction within and between groups regarding goals and vision achievements". Leaders in VTs are viewed as those who can motivate, able to achieve maximum task achievement, manage conflict and obtain team member satisfaction. Successful leaders will establish a personal relationship with their team members, which promotes trust and cohesion (Paul et al. 2016). Virtual settings create challenges for leaders, such as leading remotely, building relationships and trust between team members and handling conflict. With the absence of face-to-face interaction, the leaders' jobs are harder to perform. For example, differences in cultural background may cause a message to be interpreted incorrectly, which can cause conflict between members. The leader must stimulate their team members through the effective use of communication and motivational skills. Challenges in virtual settings require some characteristics to be embedded with leaders, such as leadership strategies, communication techniques, different personal skills, and the ability to collaborate and communicate across all boundaries (Eisenberg et al. 2019). There are three leadership styles studied in the literature: transactional, laissez-fair and transformational; the most important style and the one that gathers much attention in the literature is transformational leadership (Acai et al. 2018; Derven 2016; Gibbs et al. 2017; Plotnick et al. 2016; Al Zain et al. 2018).

Transformational leadership is a leadership style that motivates followers, enabling them to reach their potential and achieve a maximum level of performance, which will result in a high level of team performance. Transformational leadership is about motivating, influencing, having consideration for the individual and providing intellectual stimulation of behavior (Eisenberg et al. 2019). Successful leaders in VTs adopt the transformational leadership style that will be effective for the achievement of the team's objectives and leads members to optimal performance (Maduka et al. 2018). Transformational leaders are sensitive for both relationships and results. They create cohesion, use complementary skills when hiring team members and capture the best ideas when reaching a decision (Derven 2016). There are behaviors that are associated with transformational leaders: idealized influence (the extent to which his followers admire the behavior of the leader), intellectual stimulation (the extent to which leaders challenge assumptions and take a risk), inspirational motivation (the degree that followers view their leader mission/vision as appealing) and individual consideration (the degree to which the leader acts as a mentor). These four behaviors in transformational leaders will enhance the decision-making processes (Mohaghegh and Furlan 2020). Transformational leaders promote loyalty, trust, admiration, and respect among followers. This style of leadership is very important for VT performance and has a positive effect on decision-making processes (Maduka et al. 2018). Transformational leadership encourages employees to participate in independent decisionmaking (Parveen 2019). VTs that work under the transformational leadership style generate more accurate decision making than those who work under different leadership styles (Mukherjee 2012). The transformational leadership style has a positive effect on problemsolving tasks and decision-making processes (Anak Manggai et al. 2019; Chang and Lee 2013). Based on the above, we propose the following hypothesis regarding transformational leadership effects on team performance.

Hypothesis 2 (H2). Transformational Leadership have a positive effect on VT decision-making processes.

Culture Intelligence. Nowadays, companies include workers with multiple nationalities that communicate to achieve organizational goals. It is very important to understand how culture influences the work, particularly that which is related to decision-making processes. Studying the values that drive people behavior is important to understand how people will make or reach a decision. Cultural differences can cause negative behaviors 
between team members, because culture is the main source from where we drive our internal attitudes and values (Harzing and Pudelko 2014). Structures and systems people create in the organization play a significant role in transferring the shared features of culture from one generation to another. Individuals feeling, behaviors and thinking are guided by their cultures. Culture shapes the way people collect, process, and gather information. It also shapes how information is processed and what kind of explanations individuals give to explain why they reach such a decision. Culture shapes the degree to which decision is affected (Glazer and Karpati 2018). Culture is defined as the shared values, traits, and behaviors by people in a specific region (Duran and Popescu 2014). VT members with different cultures interpret and process the information needed for decisions differently. The interpretation and analysis of information depend on the individual national culture background (Paul and Dennis 2018).

According to research, individuals with certain cultures pursue decisions based on their preferences and values, while members of other cultures seek advice before making a decision (Yates and Oliveira 2016). Individuals accumulate knowledge while working in the social system, where they present their social values and share them among cultural members, which guides their decisions and behaviors (Guan and Chen 2015). Culture is an important factor in decision making. The individual needs to understand and be educated about cultural norms, values, and beliefs to understand others' frame of mind before reaching a decision. This makes decision makers in some cultures make decisions without consulting others. People frame their understanding of a situation based on their previous experience scenarios and these understanding are affected and framed by culture. Individuals are able to access, interpret and retrieve information to make sense of the events. Culture plays an important role in shaping how individuals construct and impose meaning on certain situations (Glazer and Karpati 2018). Even when exposed to the same information, people from different cultures will interpret the information differently, either as a threat, an opportunity or neither (Yates and Oliveira 2016). Among the scholars cited, the work that is the most influential in the study of culture is Hofstede (Harzing and Pudelko 2014). There are four cultural dimensions defined by Hofstede-power distance, uncertainty avoidance, individualism, and masculinity vs. femininity (Duran and Popescu 2014):

1. Individualism vs. Collectivism: It has received a substantial amount of research The culture of individualism focuses on and gives great autonomy to the individual to achieve and pursue goals (Yates and Oliveira 2016). An individualistic culture emphasizes individual efforts and uniqueness, while a collectivist culture emphasizes group needs, which are more important than individual needs (Glazer and Karpati 2018). Individualism emphasizes the priority of personal goals over group goals (Guan and Chen 2015). Each one is expected to work with the group to achieve the goals and objectives. These differences present different styles in decision making between the different cultures. Cultures that are individualistic appear to view decision making as desirable (Yates and Oliveira 2016).

2. Power distance: Individuals in power distance culture accept that power is not distributed equally and reinforce a strict hierarchy between the supervisor and its subordinates, with the supervisors as the only ones responsible for making decisions in the team.

3. Masculinity vs. Femininity: Masculinity-driven cultures emphasize the different roles between men and women, and emphasize achievements and wealth and solve conflicts through force. Femininity-driven cultures emphasize social networks and environmental welfare. The latter reach decisions through open conversation and consensus.

4. Uncertainty avoidance: The culture of uncertainty avoidance emphasizes structures, roles and policies, and procedures. In contrast, low uncertainty avoidance cultures are more tolerant to ambiguity and open to creativity, and maybe people are less stressed at work. Low tolerance for ambiguity in organizations can be easy spotted. People 
inside these organizations ask many questions or have several discussions before reaching a decision (Glazer and Karpati 2018).

Hall has argued that cultures express themselves differently through communication. Hall divided the communication of culture into two types: low-context and high-context communication. In high-context communication, cultures use contextual elements, such as body language and tone of voice, while low-context culture information is passed through the explicit use of language and rules (Harzing and Pudelko 2014). The different cultures among VT members create challenges in commination and decision making. However, cultural intelligence (CQ) reduces the negative effect that cultural diversity brings and enhances decision-making processes (Wood and St. Peters 2014). CQ can reduce the negative relationship and task performance that can be the result of culture dissimilarities. VT members with high levels of CQ will not be affected by culture diversity challenges, whether it is a deep level or surface level diversity, which will positively affect decisionmaking processes (Presbitero 2019). A lack of cultural intelligence among team members will lead to misunderstanding, conflict, and reduced trust, which will negatively affect decision-making processes (Shaik et al. 2020). Cultural intelligence is defined as "a person's capability for successful adaptation to new cultural settings, that is, for unfamiliar settings attributable to cultural context".

Cultural intelligence is a four-dimensional construct and is operationalized as culture quotient (CQ) (Shaik et al. 2020). The four dimensions of this construct are: (1) metacognition, which refers to the processes applied by individuals to understand knowledge about various cultures (Wood and St. Peters 2014); (2) cognitive, which includes the knowledge individuals have about the values and norms of the culture; (3) motivational, which is the ability of individuals to direct their efforts into learning, comprehending, and understanding the characteristics of diverse cultures and to engage in cross-cultural communication despite the challenges it can bring (Bernardo and Presbitero 2018); and (4) behavioral, which is concerned with the action created by employees in diverse cultures through verbal and non-verbal actions. CQ represents the ability of individuals to function in different cultural contexts (Wood and St. Peters 2014). Based on the above review of the literature, we can conclude that CQ helps to mitigate the negative effect that cultures impose on VT members, and we propose the following hypothesis:

Hypothesis 3 (H3). Cultural intelligence (CQ) has a positive effect on decision-making processes in VTs.

To conclude, scholars who are experts in the VT field suggest the following factors that have a significant impact on VTs' decision making: cultural intelligence, transformational leadership, and relationship and task conflict. Thus, after identifying these factors and formulating hypotheses, we will empirically test the significance of such hypotheses by performing correlational studies, which are performed in the next section.

\subsection{Research Model}

This section tests our model, presented in Figure 1, using the empirical procedure. The aim was to test the theoretical model based on real-life situations. To obtain this, first, a survey on Google forms was developed and sent to employees in IT industry companies working in virtual teams. Secondly, we used the structural equational model (SEM) to test the hypotheses and third, we present the results. 


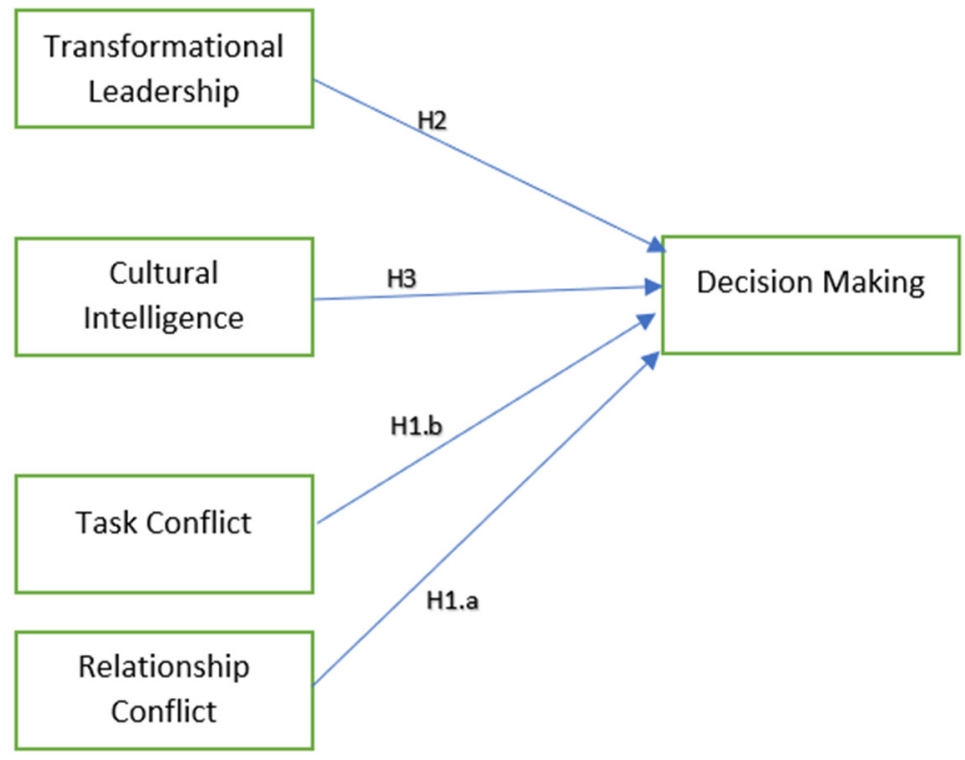

Figure 1. Factors affecting decision making.

Based on the literature review, we developed the questionnaires. The data needed for this study were obtained through a self-administrated internet survey (Google forms) consisting of 27 questions for people who work in virtual team. The number of Likert-type response options from 1 to 5 was chosen in the survey, where 1 strongly disagrees and 5 strongly agree. To acquire the data sample, members who work in virtual teams in the IT industry in the United Arab of Emirates (UAE) were identified. The targeted organizations were IT service companies, providing consultant service in enterprise resource planning (ERP), business intelligence (BI) and expert knowledge information and communication technologies (ICT). These companies have multiple branches worldwide, and their teams communicate using ICT. We used companies in IT industry since members in IT companies work virtually and their team members are spread across worldwide; however, the data collected were only for teams based in UAE. The survey was sent to 1027 employees, and we received 402 responses, which is the acceptable sample for using the structural equational model (SEM). It exceeded the minimum number of 200, given the number of observed and latent variables in the model, the anticipated effect size, and the desired probability and statistical power levels recommended by (Wolf et al. 2015). We used the structural equational model (SEM) for the following reasons: first, SEM includes confirmatory factor analysis (CFA), path analysis (PA) and partial least squares path modeling; and second, it is used for assessing unobservable latent constructs. A SEM is a qualitative and quantitative technique used to show causal relationships between variables. The relationships shown in the SEM represent the researchers' hypotheses. Generally, these relationships cannot be statistically tested for directionality. Research that uses SEM is typically intended to confirm a research design rather than to explore or explain phenomena. For example, a researcher may want to examine whether the variables in a hypothesis are consistent. The model was run on AMOS 23.0 and SPSS 23. The Cronbach's alpha method was used to assess the reliability of the questionnaires used for measurement; the values to be acceptable were above 0.7 to reflect an acceptable reliability. The variables that we considered exceeded the 0.7 value. Confirmatory factor analysis (CFA) was used to determine the dimensional structure of the scale, based on eigenvalues greater than 1. The maximum likelihood method was used since it is the best method to determine the parameters of distribution that best describe the given data. The demographic data are presented in Table 2. The respondents consisted of 299 males $(74.43 \%)$ and 103 females (25.62\%). 
Table 2. Demographics.

\begin{tabular}{cc}
\hline Details & Percentage \\
\hline \multirow{2}{*}{ Gender } & Male: 74.43 \\
& Female: 25.62 \\
\hline \multirow{3}{*}{ Mode of Communication } & Online: 26.1 \\
& Face-to-face: 6.2 \\
Designation & Both online and face-to-face: 67.67 \\
& Team member: 92 \\
Age & Team leader: 8 \\
\hline & $22-29: 36$ \\
& $30-49: 50.7$ \\
Work experience in years as a virtual team & $>50: 13.18$ \\
member & $<1: 32.33$ \\
& $<1$ and $<5: 51.49$ \\
& $<5$ and $<10: 9.95$ \\
\end{tabular}

A total of 272 respondents (67.67\%) use both online and face-to-face while communicating with other teams; 25 respondents $(6.2 \%)$ use only face-to-face; and 105 respondents (26.1\%) only use online communication with virtual teams. A total of $92 \%$ of respondents (370) were team members, and $8 \%$ of respondents (32) were team leaders. A total of 145 respondents $(36 \%)$ were in the age group from $22-29,204$ respondents $(50.7 \%)$ in the age group between 30 and 39, and $13.18 \%$ (53) respondents were above 50 years old. A total of $32.33 \%$ (130) of respondents had less than 1 year of experience in VT, $51.49 \%$ (207) had between 1 and 5 years, 9.95\% (40) had 6-10 years of expertise working in VT and 6.21\% (25) had over ten years of experience in VT.

\section{Results and Discussion}

To compare the proposed hypotheses, the structural equations model shown in Figure 2 was developed. Figure 2 shows the measurement model of SEM, where each of the latent variable is represented by five measured variables, called indicators. The indicators can be found in Appendix A, which describes each questionnaire used. The current study sought to examine the factors that affect decision making inside virtual teams. The structural equation modeling (SEM) technique with the help of AMOS 23.0 was used to test the research question of the study. We used the maximum likelihood method.

To validate the measurement model, we assessed its convergent and discriminant validity. The standardized path loadings of all items were significant and exceeded 0.5. The composite reliability (CR) exceeded 1.96 and the average variance extracted (AVE) exceeded 0.5. Thus, convergent validity was supported. We calculated the maximum squared variance, and it was less than AVE, thus discriminant validity was supported. Multicollinearity also tests the correlation between independent variables and was less than 0.3 , so there were no multicollinearity issues. The model fit also verified the results for CFI, SRMR, RMSEA, and PCLOSE, which were acceptable, as the results shown in Table 3 demonstrate. Table 3 shows the fit indices for the structural equational model; the chi-square, which is called CMIN, is divided by the degree of freedom (DF) and is 2.53, which is between 1 and 3. The comparative fit index (CFI) is 0.92 , which is above 0.90; the standardized root mean square residual (SRMR) and root mean square error of approximation (RMSEA) are below the threshold, as shown in Table 3. PClose, which offers a test for close fit, is 0.06 , which is above the threshold 0.05 and results in model fit. 


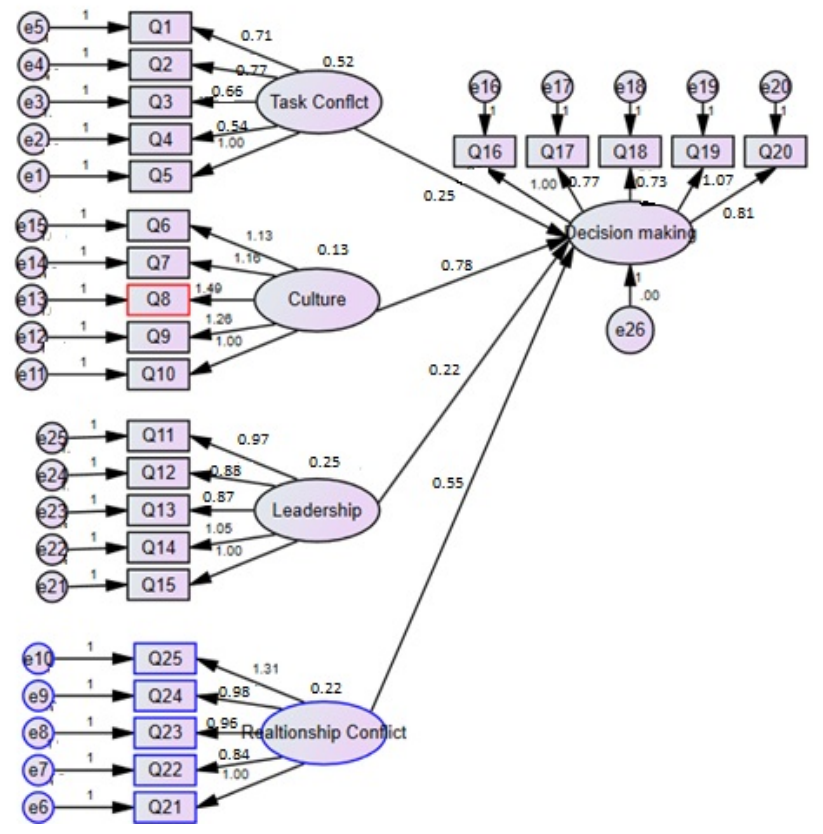

Figure 2. Decision-making module.

Table 3. Model Fit.

\begin{tabular}{cccc}
\hline Measure & Estimate & Threshold & Interpretation \\
\hline CMIN & 1117 & - & - \\
DF & 376 & - & - \\
CMIN/DF & 2.53 & Between 1 and 3 & Acceptable \\
CFI & 0.92 & $>0.90$ & Acceptable \\
SRMR & 0.052 & $<0.08$ & Acceptable \\
RMSEA & 0.036 & $<0.06$ & Acceptable \\
PClose & 0.06 & $>0.05$ & Acceptable \\
\hline
\end{tabular}

The model was tested by collecting the data through an online survey and using the AMOS SPSS software. The results indicate, as shown in Table 4, that Composite reliability (CR) is above 2 for all factors, and estimate is below 0.7 , and standard errors less than 0.3 , and p-value is less than 0.05 which means that all factors are significantly different from zero at the 0.05 level (two-tailed), in other words relationship conflict (H1.a), task conflict (H1.b), transformational leadership (H2) and cultural intelligence (H3) are significant. Task conflicts enhance and stimulate communication, the sharing of information and generation of new ideas, which enhance and facilitate the decision-making process. The relationship conflict blocks communication and the sharing of ideas between team members, which will badly affect the decision-making processes, and thus lead to improper decisions. Transformational leadership stimulates, motivates, and encourages employees to communicate and exchange information, resulting in proper decision making. Cultural intelligence is one of the most important factors that enhance decision making since it enables the team members to work and cope in different cultural settings, which will lead to enhanced decisions.

Table 4. Data results.

\begin{tabular}{ccccccc}
\hline Hypotheses & Factors & Estimate & Standard Error & CR & $p$-Value & Result \\
\hline H1.a & Task Conflict & 0.246 & 0.065 & 3.787 & $* * *$ & Supported \\
H1.b & Relationship Conflict & 0.554 & 0.135 & 4.110 & $* * *$ & Supported \\
H2 & Culture & 0.783 & 0.212 & 3.687 & $* * *$ & Supported \\
H3 & Leadership & 0.221 & 0.090 & 2.461 & 0.014 & Supported \\
\hline
\end{tabular}

Note: ${ }^{* * *} p<0.001$. 
There are four key findings in our analysis affecting decision-making processes. We found that task conflict, transformational leadership, and cultural intelligence effect decision making positively and have a significance $p$-value $<0.05$, using a 95\% confidence interval, while relationship conflicts negatively affect decision-making processes. Our goal in in this study was to discover some of the factors that enhance decision making in VTs in systematic ways. We did not attempt to explain all the factors that exist and have a direct effect on VT decisions, but we identified four key research factors that are the most prominent: conflict, relationship conflict, transformational leadership, and cultural intelligence. We developed propositions to aid future research in each of them. This article provides the broader implications of our analysis for the decision making of virtual teams based on the findings and implications from each of these four areas. The theoretical implications are as follows:

Implications for Transformational Leadership. Student samples used in leadership studies may be missing a large part of the picture. Leaders of organizations are often expected to take on many more responsibilities than those of classrooms or lab-based student projects. Researchers who work with virtual teams must be more careful in how they conceptualize and operationalize leadership and should strive for consistency across the studies, or should state their boundary conditions more clearly (Gibbs et al. 2017). A theoretical implication of this study regarding TL is that it draws upon other researchers' studies of decision making in virtual teams, where the transformational leadership paradigm has been applied. Even though more empirical research is needed to understand how different types of leadership play out in a variety of virtual teams, this study makes an important contribution by studying TL in a real workplace. For TL, the findings reveal that it helps VTs to make better decisions. Therefore, transformational leadership plays a critical role in enhancing VT decision-making processes. Our results add to the literature on TL by supporting the hypothesis "H2: transformational leadership has a positive effect on VT decision-making processes", and coincide with the previous literature that was conducted on the effects of TL on decision making in the U.S.A. and Europe. Based on the present research, transformational leaders are well suited to lead virtual teams in an IT organization by enhancing decision making in VT through their TL style behaviors. These findings have implications for the study of leadership in virtual teams. They suggest that effective leadership may differ based on the transformational leadership style that is chosen in VTs, since TL in VTs must negotiate roles and relationships and is accountable for the outcomes. This suggests that scholars should more explicitly consider transformational leadership in their research.

Implications for Culture. The literature on multicultural teams and virtual teams has been largely separated, making it difficult to study intercultural decision-making concerns in virtual team research. There are many studies that adopt implicit assumptions about VT decision making that are not applicable to other cultures. Our research calls for future research to examine the intersection of the cultural effects on VT decision making through the use of organizational field studies to foster intercultural competence and a cosmopolitan orientation among team members. Moreover, in our study, we extended the concept of culture beyond simple nationality measures by including more complex cultural orientations, since organizations in U.A.E. include individuals from all over the world (Gibbs et al. 2017; Presbitero 2021). For CQ, the results support previous research conducted in the field that shows that CQ positively affects decision-making processes in VTs. Our results support our proposed hypothesis and add to the current literature on CQ effects on VTs.

Implications for Conflict. Our study contributes to the management of conflict by studying two factors, relationship and task conflict, and their effect on VT decision making. Conflict management is one of the biggest challenges that teams face in virtual settings due to its impact on individual, team, and organizational performance. Our results support previous research conducted in the field and show that conflict positively and negatively 
affects decision-making processes in VTs. Our results support our proposed hypotheses and thus add to the current literature on the effects of conflict on VTs.

Finally, our study helps to enrich VT decision making. Given that VT decision making is a complex process, and different factors affect it vary widely, these findings provide empirical evidence of the effect of the following factors on VT decision making to support and measure the appropriateness of decision making in VT. In addition, rigorous measures were used to test the model; positive relationships were found between cultural intelligence (CQ), transformational leadership (TL), and task conflict on VT decision making; and negative relation were found between the relationship conflict and VT decision making. This paper contributes to a better understanding of the decision-making processes within a virtual team to maximize the chances of success in this type of organization. Several compelling research trends and questions for future research emerged in our literature review, all firmly grounded in multicultural and virtual team leadership research and recent work on biculturalism, which deliberately poses questions regarding leadership, culture, and conflict on global teams.

Aside from the theoretical contribution that this study has to the literature, the findings have practical implications. The model shows that the following variables, culture intelligence (CQ), transformational leadership (TL), and task and relationship conflict, are the most important variables to consider when measuring VT decision making, especially because of the increase in virtualization and teleworking due to the emergence of the COVID-19 pandemic. First, this study provides a new approach for managing decision making in VTs. Management can be guided on how to manage and enhance their VT decisions. This is very beneficial for an organization to build strong teams that can reach optimal decision-making processes. For existing virtual teams, managers can measure the quality of decision-making processes and work to enhance the factors influencing decisionmaking processes, which in turn enhances the decision-making process inside the team and thus its performance. When hiring new team members, organizations must take into consideration these factors and hire members that have cohesion with the existing team members. These models form the basis for organizations in developing countries to build upon when measuring VT decision making and virtual team performance, and it can be further integrated with new modules that propose implementation plans to help to create high performing VTs. For example, finding a new practice to handle conflict between team members will enhance the decision-making process, and if they find any problems with the new approach, a suitable intervention can be applied, such as regular virtual meetings to discuss the plans and any other goals to be delivered, including schedules and timelines, since these are the most important and relevant factors, especially because of the increase in virtualization and teleworking during the COVID-19 pandemic. These factors must be given a higher priority by companies to enhance their VT decision making.

Second, management should assure the following factors are developed and learned over time: CQ, TL, how to handle conflict, both task and relationship conflicts, through training. This will allow VTs to develop their competency, resulting in enhanced decisionmaking processes among VTs. Virtual team management is a multidimensional topic and this study provides meaningful implications for virtual team leaders. It aims to help managers to learn the dynamics of performance management and organizational performance very well in virtual settings, and it facilitates the achievement of their organizational goals. It also helps team leaders to review their leadership characteristics and the abilities and to broaden their horizons regarding performance management. This study suggests that the following factors are variables to take into consideration for improving the decisionmaking process in VTs. VT members have to be oriented towards culture intelligence (CQ), transformational leadership (TL), and both task and relationship conflicts. There has to be a way to monitor how members demonstrate communication accommodation (one way is through their performance appraisal, meaning that it has to be included as part of the evaluated performance indicators in VTs) and consequently it should be reinforced and strengthened through rewards and recognitions. Regarding conflict, it can be performed 
through the proper communication between team members and using the proper channel, since lack of non-verbal features of communication, including gestures, body language, and facial expressions, especially when communication is conducted through e-mails, can trigger conflict. For example, on many occasions, a simple question/query sounds interrogatory and reproachful, resulting in negative feelings and misunderstandings. Therefore, as much as possible, the discussion of problems should be conducted via videoconferencing and other useful synchronous media. Thus, we can see that, by keeping in mind such simple and inexpensive action steps, virtual team leaders can increase the productivity and commitment of their dispersed work teams.

Finally, this study opens the way for future research investigations on the factors that should be employed to improve the VT decision-making processes in IT organizations.

\section{Conclusions}

VT decision making is an important key indicator of VT performance, and hence organizational performance. Organizations must understand and measure the key factors that affect decision making and team performance in an organization and work to enhance it to be able to obtain its market share and be competitive. This article aimed to identify the following factors- $\mathrm{CQ}, \mathrm{TL}$, and task and relationship conflict- that affect VT decisionmaking processes. Based on the empirical research conducted, it can be concluded that $\mathrm{CQ}$, $\mathrm{TL}$, and task and relationship conflict are important factors to consider when measuring VT decisions, as the results show that culture intelligence (CQ), transformational leadership (TL), and task conflict are positively correlated with decision-making processes, and relationship conflict is negatively correlated with decision-making processes in VTs. This article provides a guideline for management in an organization to measure VT decision making. For example, when measuring decision making in VT, management should concentrate on how to enhance the following factors-cultural intelligence, transformational leadership, and task conflict-and how to eliminate or reduce relationship conflict factors between members in VTs. Measuring and controlling these factors will help an organization to enhance its VT decisions, which in turn will improve VT performance. In addition, this study proposes a framework for future studies to add factors to these models and create new models, not only to measure but also to implement strategies that can be used to enhance the VT decision-making process and hence improve VT performance. As all research does, this study has limitations. The first limitation of this study is the use of four factors affecting decision-making processes. However, there are other factors that affect decision making that were not included in this study, such as trust, ICT, etc. Second, the study was conducted among organizations in the IT industry. Future studies should include other industries. Third, this study was conducted in the U.A.E. Future studies should include countries in the Middle East in comparison with other regions. Future studies also should include all the mentioned limitations.

Author Contributions: Conceptualization is delivered by K.A.M. and V.D.; writing-original draft preparation is made by K.A.M.; writing-reviewing and editing are given by V.D., and methodology is constructed by K.A.M. and V.D. All authors have read and agreed to the published version of the manuscript.

Funding: This research received no external funding.

Conflicts of Interest: The authors declare no conflict of interest. 


\section{Appendix A}

\begin{tabular}{|c|c|c|c|c|c|c|}
\hline \multicolumn{7}{|c|}{ I. Task Conflict } \\
\hline & $\begin{array}{c}\text { ITEMS } \\
\end{array}$ & Strongly Disagree & Disagree & Neutral & Agree & Strongly Agree \\
\hline Q1 & $\begin{array}{l}\text { Task conflict provides a conduit to } \\
\text { actualize the benefits of cognitive } \\
\text { diversity on decision outcomes. }\end{array}$ & & & & & \\
\hline Q2 & $\begin{array}{l}\text { Task conflict enhances the sharing of } \\
\text { important information during the } \\
\text { reaching of a decision. }\end{array}$ & & & & & \\
\hline Q3 & $\begin{array}{l}\text { Task conflict will likely occur during the } \\
\text { process of creating alternatives. }\end{array}$ & & & & & \\
\hline Q4 & $\begin{array}{l}\text { Task conflict will result in the ommitment } \\
\text { to a decision. }\end{array}$ & & & & & \\
\hline Q5 & $\begin{array}{l}\text { There are many disagreements over } \\
\text { different ideas about decisions. }\end{array}$ & & & & & \\
\hline \multicolumn{7}{|c|}{ II. Cultural Intelligence } \\
\hline & $\begin{array}{r}\text { ITEMS } \\
\end{array}$ & Strongly Disagree & Disagree & Neutral & Agree & Strongly Agree \\
\hline Q6 & $\begin{array}{l}\text { I know the ways in which cultures in my } \\
\text { team present differences in the } \\
\text { decision-making process. }\end{array}$ & & & & & \\
\hline Q7 & $\begin{array}{l}\text { I can accurately understand the feelings } \\
\text { of people from other cultures before } \\
\text { agreeing on a decision. }\end{array}$ & & & & & \\
\hline Q8 & $\begin{array}{l}\text { I think a lot about the influence that } \\
\text { culture has on my behaviour and that of } \\
\text { others who are culturally different than } \\
\text { me when agreeing on decision making. }\end{array}$ & & & & & \\
\hline Q9 & $\begin{array}{l}\text { I am aware that I need to plan my course } \\
\text { of action when I am in different situations } \\
\text { and with culturally different people. }\end{array}$ & & & & & \\
\hline Q10 & $\begin{array}{l}\text { I accept delays without becoming upset } \\
\text { when I am in different cultural situations. }\end{array}$ & & & & & \\
\hline \multicolumn{7}{|c|}{ III. Transformational Leadership } \\
\hline & ITEMS & Strongly Disagree & Disagree & Neutral & Agree & Strongly Agree \\
\hline Q11 & $\begin{array}{l}\text { Our leader involved members in } \\
\text { decision-making processes. }\end{array}$ & & & & & \\
\hline Q12 & $\begin{array}{l}\text { Our leader involved members in the } \\
\text { selection of decision alternatives. }\end{array}$ & & & & & \\
\hline Q13 & $\begin{array}{l}\text { Our leader involved members in the } \\
\text { sharing and gathering of information. }\end{array}$ & & & & & \\
\hline Q14 & $\begin{array}{l}\text { Our leader controled the decision-making } \\
\text { processes. }\end{array}$ & & & & & \\
\hline Q15 & $\begin{array}{l}\text { Leaders who collect extensive } \\
\text { information will have better } \\
\text { decision-making abilities. }\end{array}$ & & & & & \\
\hline
\end{tabular}




\begin{tabular}{|c|c|c|c|c|c|c|}
\hline \multicolumn{7}{|c|}{ IV. Relationship Conflict } \\
\hline & ITEMS & Strongly Disagree & Disagree & Neutral & Agree & Strongly Agree \\
\hline Q16 & $\begin{array}{l}\text { Relationship conflicts cause the } \\
\text { withholding of information during } \\
\text { decision-making processes. }\end{array}$ & & & & & \\
\hline Q17 & $\begin{array}{l}\text { How much anger was there among the } \\
\text { group over the decision. }\end{array}$ & & & & & \\
\hline Q18 & $\begin{array}{l}\text { How much personal friction was there in } \\
\text { the group during the decision. }\end{array}$ & & & & & \\
\hline Q19 & $\begin{array}{l}\text { How much were personality clashes } \\
\text { between group members evident during } \\
\text { the decision. }\end{array}$ & & & & & \\
\hline Q20 & $\begin{array}{l}\text { How much tension was there in the group } \\
\text { during the decision. }\end{array}$ & & & & & \\
\hline
\end{tabular}

\begin{tabular}{|c|c|c|c|c|c|c|}
\hline \multicolumn{7}{|c|}{ V. Decision-Making Processes } \\
\hline & $\begin{array}{l}\text { ITEMS } \\
\end{array}$ & Strongly Disagree & Disagree & Neutral & Agree & Strongly Agree \\
\hline Q20 & $\begin{array}{l}\text { Understanding the problems will result in } \\
\text { effective decision making. }\end{array}$ & & & & & \\
\hline Q20 & $\begin{array}{l}\text { Adequate gathering of informing will } \\
\text { result in effective decision making. }\end{array}$ & & & & & \\
\hline Q20 & $\begin{array}{l}\text { Choosing the best alternative will result } \\
\text { in effective decision making. }\end{array}$ & & & & & \\
\hline Q20 & $\begin{array}{l}\text { Adequate analysis of information will } \\
\text { result in effective decision making. }\end{array}$ & & & & & \\
\hline Q20 & $\begin{array}{l}\text { Generating all possible alternatives will } \\
\text { result in effective decision making. }\end{array}$ & & & & & \\
\hline Q20 & $\begin{array}{l}\text { Choosing the best alternative from the set } \\
\text { of generated alternatives will result in } \\
\text { effective decision making. }\end{array}$ & & & & & \\
\hline Q20 & $\begin{array}{l}\text { The team will analyse the problem in } \\
\text { depth before searching for a solution. }\end{array}$ & & & & & \\
\hline Q20 & $\begin{array}{l}\text { The team will generate alternatives before } \\
\text { searching for a solution. }\end{array}$ & & & & & \\
\hline Q20 & $\begin{array}{l}\text { The team will choose the best alternatives } \\
\text { in searching for a solution. }\end{array}$ & & & & & \\
\hline Q20 & $\begin{array}{l}\text { The team knows the consequence of } \\
\text { understanding the problem before } \\
\text { implementing each alternative. }\end{array}$ & & & & & \\
\hline Q20 & $\begin{array}{l}\text { The team know the consequence before } \\
\text { generating possible alternatives. }\end{array}$ & & & & & \\
\hline Q20 & $\begin{array}{l}\text { The team knows the best alternative to } \\
\text { apply. }\end{array}$ & & & & & \\
\hline Q20 & $\begin{array}{l}\text { The team made a decision based on good } \\
\text { practices (after collecting all the } \\
\text { information). }\end{array}$ & & & & & \\
\hline Q20 & $\begin{array}{l}\text { The team made a decision based on good } \\
\text { practices (considering all the alternatives). }\end{array}$ & & & & & \\
\hline Q20 & $\begin{array}{l}\text { The team made a decision based on good } \\
\text { practices (after choosing the best } \\
\text { alternative). }\end{array}$ & & & & & \\
\hline
\end{tabular}




\section{References}

Acai, Anita, Ranil R. Sonnadara, and Thomas A. O'Neill. 2018. Getting with the Times: A Narrative Review of the Literature on Group Decision Making in Virtual Environments and Implications for Promotions Committees. Perspectives on Medical Education 7: 147-55. [CrossRef] [PubMed]

Al Majzoub, Khaled, and Vida Davidavičienè. 2018. Organization Behavior Changes Caused By Information and Communication Technologies. Paper presented at the 10th International Scientific Conference, Vilnius, Lithuania, May 3-4; pp. 19-25. [CrossRef]

Al Zain, Nora-Labiba, Simona Vasilache, and Cynthia Bianka Incze. 2018. The Significance and Managerial Challenges of Virtual Teamworking. Paper presented at the International Conference on Business Excellence, Bucharest, Romania, March 22-23; vol. 12, pp. 25-33. [CrossRef]

Anak Manggai, Bibiana, Kassim Bin Thukiman, Muhammad Fauzi Bin Othman, and Evalian J. Simon. 2019. Transformational leadership and ethical decision making. Paper presented at the ASIA International Multidisciplinary Conference Transformational, Johor Bahru, Malaysia, May 12-13. [CrossRef]

Bartelt, Valerie L., Alan R. Dennis, Lingyao Yuan, and Jordan B. Barlow. 2013. Individual Priming in Virtual Team Decision-Making. Group Decision and Negotiation 22: 873-96. [CrossRef]

Bernardo, Allan B. I., and Alfred Presbitero. 2018. Cognitive Flexibility and Cultural Intelligence: Exploring the Cognitive Aspects of Effective Functioning in Culturally Diverse Contexts. International Journal of Intercultural Relations 66: 12-21. [CrossRef]

Bhat, Swati Kaul, Neerja Pande, and Vandana Ahuja. 2017. Virtual Team Effectiveness: An Empirical Study Using SEM. Procedia Computer Science 122: 33-41. [CrossRef]

Carita, Snellman. 2014. Virtual Teams: Opportunities and Challenges for e-Leaders. Procedia—Social and Behavioral Sciences 110: $1251-61$. [CrossRef]

Chang, Hsin Hsin, Chung-jye Hung, and Hsu-wei Hsieh. 2014. Total Quality Management \& Business Excellence Virtual Teams: Cultural Adaptation, Communication Quality, and Interpersonal Trust. Total Quality Management E Business Excellence 25: 1318-35. [CrossRef]

Chang, Wen-long, and Chun-yi Lee. 2013. Virtual Team E-Leadership: The Effects of Leadership Style and Conflict Management Mode on the Online Learning Performance of Students in a Business-Planning Course. British Journal of Educational Technology 44: 986-99. [CrossRef]

Chrobot-mason, Donna, Marian N. Ruderman, Todd J. Weber, J. Patricia, and Maxine A. Dalton. 2011. Illuminating a Cross-Cultural Leadership Challenge: When Identity Groups Collide. The International Journal of Human Resource Management 18: $2011-36$. [CrossRef]

Cordes, Sean. 2016. Virtual Team Learning: The Role of Collaboration Process and Technology Affordance in Team Decision Making. Knowledge Management and E-Learning 8: 602-27. [CrossRef]

Davidaviciene, Vida, Khaled Al Majzoub, and Ieva Meidute-Kavaliauskiene. 2020. Factors Affecting Decision-Making Processes in Virtual Teams in the UAE. Information 11: 490. [CrossRef]

Davidavičiene, Vida, Khaled Al Majzoub, and Ieva Meidute-Kavaliauskiene. 2020. Factors Affecting Knowledge Sharing in Virtual Teams. Sustainability 12: 6917. [CrossRef]

Derven, Marjorie. 2016. Four Drivers to Enhance Global Virtual Teams. Industrial and Commercial Training 48: 1-8. [CrossRef]

Drouin, Nathalie, and Mario Bourgault. 2013. How Organizations Support Distributed Project Teams Key Dimensions and Their Impact on Decision Making and Teamwork Effectiveness. Management Development 32: 865-85. [CrossRef]

Duran, Vasile, and Anca-Diana Popescu. 2014. The Challenge of Multicultural Communication in Virtual Teams. Procedia-Social and Behavioral Sciences 109: 365-69. [CrossRef]

Eisenberg, Julia, Corinne Post, and Nancy Ditomaso. 2019. Team Dispersion and Performance: The Role of Team Communication and Transformational Leadership. Small Group Research 50: 348-80. [CrossRef]

Gao, Shuli, Yanli Guo, Jianbin Chen, and Lin Li. 2016. Factors Affecting the Performance of Knowledge Collaboration in Virtual Team Based on Capital Appreciation. Information Technology and Management 17: 119-31. [CrossRef]

Gibbs, Jennifer L., Anu Sivunen, and Maggie Boyraz. 2017. Investigating the Impacts of Team Type and Design on Virtual Team Processes. Human Resource Management Review 27: 590-603. [CrossRef]

Glazer, Sharon, and Tamas Karpati. 2018. The Role of Culture in Decision Making. Cutter IT 27: 339-66. [CrossRef]

Guan, Yanjun, and Sylvia Xiaohua Chen. 2015. Differences in Career Decision- Making Profiles Between American and Chinese University Students: The Relative Strength of Mediating Mechanisms Across Cultures. Cross-Cultural Psychology 46: 856-72. [CrossRef]

Harzing, Anne-wil, and Markus Pudelko. 2014. Comprehensive Overview of the Role of Language Differences in HeadquartersSubsidiary Communication. Human Resource Management 25: 696-717. [CrossRef]

Johnson, Kevin J., Joé T. Martineau, Saouré Kouamé, Gokhan Turgut, and Serge Poisson-de-Haro. 2018. On the Unethical Use of Privileged Information in Strategic Decision-Making: The Effects of Peers' Ethicality, Perceived Cohesion, and Team Performance. Journal of Business Ethics 152: 917-29. [CrossRef]

Kiernan, Louise, Ann Ledwith, and Raymond Lynch. 2019. Design Teams Management of Conflict in Reaching Consensus. International Journal of Conflict Management 31: 263-85. [CrossRef]

Li, Ye, Pei Luen Patrick Rau, Hui Li, and Alexander Maedche. 2017. Effects of a Dyad's Cultural Intelligence on Global Virtual Collaboration. IEEE Transactions on Professional Communication 60: 56-75. [CrossRef] 
Lowry, Paul Benjamin, Ryan M. Schuetzler, Justin Scott Giboney, and Thomas A. Gregory. 2015. Is Trust Always Better than Distrust? The Potential Value of Distrust in Newer Virtual Teams Engaged in Short-Term Decision-Making. Group Decision and Negotiation 24: 723-52. [CrossRef]

Maduka, Nnamdi Stanley, Helen Edwards, David Greenwood, Allan Osborne, and Solomon Olusola Babatunde. 2018. Analysis of Competencies for Effective Virtual Team Leadership in Building Successful Organisations. Benchmarking 25: 696-712. [CrossRef]

Mohaghegh, Matin, and Andrea Furlan. 2020. Systematic Problem-Solving and Its Antecedents: A Synthesis of the Literature the Literature. Management Research Review 43: 1033-62. [CrossRef]

Mukherjee, Debmalya. 2012. Leading Virtual Teams: How Do Social, Cognitive, and Behavioral Capabilities Matter? Management Decision 50: 273-90. [CrossRef]

O'Neill, Thomas A., Samantha E. Hancock, Katarina Zivkov, Nicole L. Larson, and Stephanie J. Law. 2016. Team Decision Making in Virtual and Face-to-Face Environments. Group Decision and Negotiation 25: 995-1020. [CrossRef]

Oesch, Nathan, and Robin I. M. Dunbar. 2018. Group Size, Communication, and Familiarity Effects in Foraging Human Teams. Ethology 124: 483-95. [CrossRef]

Olson, Bradley J., Satyanarayana Parayitam, and Yongjian Bao. 2007. Strategic Decision Making: The Effects of Cognitive Diversity, Conflict, and Trust on Decision Outcomes. Journal of Management 33: 196-222. [CrossRef]

Organ, Damien, and Brian O. Flaherty. 2018. Intuitive Decision-Making and Deep Level Diversity in Entrepreneurial ICT Intuitive Decision-Making and Deep Level Diversity in Entrepreneurial ICT Teams. Journal of Decision Systems 25: 421-35. [CrossRef]

Parveen, Musrrat. 2019. Transformational Leadership: Does It Really Decrease Work-Related Stress? Leadership E Organization Development Journal 40: 860-76. [CrossRef]

Paul, Ravi, John R. Drake, and Huigang Liang. 2016. Global Virtual Team Performance: The Effect of Coordination Effectiveness, Trust, and Team Cohesion. IEEE Transactions on Professional Communication 59: 186-202. [CrossRef]

Paul, Souren, and Alan R. Dennis. 2018. Group Atmosphere, Shared Understanding, and Team Conflict in Short Duration Virtual Teams. Paper presented at the 51st Hawaii International Conference on System Sciences, Waikoloa Village, HI, USA, January 2-6. [CrossRef]

Plotnick, Linda, Starr Roxanne Hiltz, and Robin Privman. 2016. Ingroup Dynamics and Perceived Effectiveness of Partially Distributed Teams. IEEE Transactions on Professional Communication 59: 203-29. [CrossRef]

Presbitero, Alfred. 2019. Foreign Language Skill, Anxiety, Cultural Intelligence and Individual Task Performance in Global Virtual Teams: A Cognitive Perspective. International Management 26: 1-13. [CrossRef]

Presbitero, Alfred. 2021. Communication Accommodation within Global Virtual Team: The Influence of Cultural Intelligence and the Impact on Interpersonal Process Effectiveness. Journal of International Management 27: 1-17. [CrossRef]

Schmidtke, James M., and Anne Cummings. 2017. The Effects of Virtualness on Teamwork Behavioral Components: The Role of Shared Mental Models. Human Resource Management Review 27: 660-77. [CrossRef]

Shaik, Farheen Fathima, Upam Pushpak Makhecha, and Sirish Kumar Gouda. 2020. Work and Non-Work Identities in Global Virtual Teams. International Journal of Manpower 3: 1-28. [CrossRef]

Susskind, Alex M., and Peggy R. Odom-reed. 2019. Team Member's Centrality, Cohesion, Conflict, and Performance in Multi-University Geographically Distributed Project Teams. Communication Research 46: 151-78. [CrossRef]

Tan, Chong King. 2019. Factors in Fl Uencing Virtual Team Performance in Malaysia. Kybernetes 48: 2065-92. [CrossRef]

Wang, Wei-tsong, Yi-shun Wang, and Wan-ting Chang. 2019. Investigating the Effects of Psychological Empowerment and Interpersonal Con Fl Icts on Employees' Knowledge Sharing Intentions. Journal of Knowledge Management 23: 1039-76. [CrossRef]

Wei, Kangning, Robert Heckman, Kevin Crowston, and Qing Li. 2017. Decision-Making Processes and Team Performance in Self-Organizing Virtual Teams: The Case of Free/Libre Open Source Software Development Teams. Citeseerx 2: 1-33.

Witman, Paul D. 2018. Teaching Case 'What Gets Measured, Gets Managed' The Wells Fargo Account Opening Scandal. Journal of Information Systems Education 29: 131-38.

Wolf, Erika, Kelly Harrington, Shaunna Clark, and Mark Miller. 2015. Sample Size Requirements for Structural Equation Models: An Evaluation of Power, Bias, and Solution Propriety Erika. Educational and Psychological Measurement 76: 913-34. [CrossRef] [PubMed]

Wood, Evan D., and Heather Y. Z. St. Peters. 2014. Short-Term Cross-Cultural Study Tours: Impact on Cultural Intelligence. International Journal of Human Resource Management 25: 558-70. [CrossRef]

Wu, Jiunyan. 2020. A Multilevel and Dynamic Model of Intragroup Conflict and Decision Making: Application of Agent-Based Modeling. Business Research in China 1: 1-26. [CrossRef]

Yates, J. Frank, and Stephanie De Oliveira. 2016. Organizational Behavior and Human Decision Processes Culture and Decision Making. Organizational Behavior and Human Decision Processes 136: 106-18. [CrossRef] [PubMed]

Zakaria, Norhayati. 2017. Emergent Patterns of Switching Behaviors and Intercultural Communication Styles of Global Virtual Teams During Distributed Decision Making. Journal of International Management 23: 350-66. [CrossRef]

Zhang, Yi, and Wanhong Zhang. 2019. How Does the Team Expertise Heterogeneity Improve Entrepreneurial Performance? Electronic Commerce Research 2016: 1-12. [CrossRef] 